\title{
A Review of Collaborative Manufacturing Network Models
}

\author{
Mohammad Rizal Firmansyah and Yousef Amer
}

\begin{abstract}
Tough competition in the current global economies has forced manufacturing enterprises, especially small and medium manufacturing enterprises (SMMEs) to collaborate with other companies to survive. They strive to manage their products to achieve a high level of customer satisfaction at a competitive price in a timely manner with the best quality. Collaborative models covering part of the whole production process have been developed providing advantages to the participating companies. Integration of these current collaborative models into a holistic collaborative manufacturing model could provide operational cost savings as well as significantly increasing competitive advantage. However, there is no current review which provides a comprehensive picture of such integration. Therefore, this study aims to provide a thorough literature review of the current collaborative models, their advantages and their collaborative components which are used to support the collaboration process. Four areas of collaborative models namely; collaborative forecasting, collaborative design and product development, collaborative manufacturing and collaborative distribution are discussed. The majority of previous works tend to overlook combinations of collaborative models in the concerned aspects. Hence, future research opportunities to bring those areas more closely linked to each other is proposed so that manufacturing enterprises can take maximum benefit from all of the current models of collaborative manufacturing.
\end{abstract}

Index Terms-Collaborative manufacturing network (CMN), models of collaborative manufacturing, SMME.

\section{INTRODUCTION}

Competition in this currently fast changing global business environment has forced manufacturing enterprises to innovate and continuously find the best way to survive. They strive to manage their products to achieve a higher level of customer satisfaction, at a competitive price, in a timely manner and with the best quality. Large enterprises seem to have no problem to keep their companies in pace with the fast changing environment since they have resources to meet the change, but in contrast, for the small and medium manufacturing enterprises (SMMEs), problem arises from the shortage of resources, and difficulties in forming industrial connections and networking [1], [2]. Several solutions have been offered by researchers for SMMEs in order for them to be competitive and overcome those challenges. Some of them are by improving product cycles,

Manuscript received November 20, 2012; revised January 10, 2013.

M. R. Firmansyah is with the School of Advanced Manufacturing and Mechanical Engineering, University of South Australia, Australia (e-mail: firmy001@mymail.unisa.edu.au) and with the Engineering Faculty, University of Hasanuddin, Indonesia (e-mail: mr.firmansyah@unhas.ac.id).

Y. Amer is with the School of Advanced Manufacturing and Mechanical Engineering, University of South Australia, Australia (e-mail: yousef.amer@unisa.edu.au). reducing cost, working concurrently in a network, and developing global strategies [3], [4]. Other researchers suggest enterprises to get involved in a collaborative manufacturing as a new manufacturing paradigm, working together as a company to fully utilize their capability and resources [4]-[6].

Collaborative manufacturing is a way forward to solve their limitations. There are some advantages for SMMEs if they are involve in a collaboration such as increasing companies skills, capacities and capabilities by sharing resources and becoming suppliers of complete systems, learning and exchanging essential information, the possibility to develop more complex product, increased global market share and decreased production cost, etc. [6]-[8]. Several others reasons stated by researchers for the need for collaboration in manufacturing enterprises are; to stay competitive and survive in the market place [9], [10], a way for a company to become more efficient and agile in the way it works with its suppliers, partners, and customers [11], increased sales and reducing operating cost while making use of new processes by working closely in partnership [12]. The impacts of collaborative manufacturing have been reported as giving significant improvement in the manufacturing processes as it improves inventory accuracy by 5\%-15\%, reduces supply chain operation cost by $20 \%-35 \%$, reduces order scheduling time by $66 \%$, channel inventory trimmed by $80 \%$ and supply commit cycle time saved by $50 \%$ [13] and [14].

Collaborative manufacturing has been defined by some researchers [11], [13], [15], and [16] as a new business paradigm where some companies work together and use their own expert competencies to manufacture a product in order to achieve the overall business network performances. A company conducting collaboration will get more benefits compared to other companies, but as the challenges in the current global market have increased significantly, then holistic and comprehensive collaboration becomes a necessity to be implemented. There are many kinds of collaboration in manufacturing that have been implemented by companies for competitiveness. Collaboration discussed by researchers are collaboration in project planning and scheduling [17], [18], collaboration in product design and development [19]-[21], collaboration in forecasting [22], [23], collaboration in production systems [24], [25] and collaboration in the supply chain [26], [27]. However, the discussions are still in the context of segmented collaboration of the whole process of a holistic collaboration.

Collaboration models explored in the literature can be divided into two categories. The first category discusses the collaboration models themselves and the second discusses the model components which are used to support the 
implementation of the collaboration. The first category can be divided into four groups based on the collaboration types which are: Collaboration on forecasting (CF), Collaboration on design and product development (CDPD), Collaboration on manufacturing (CM), and Collaboration on transportation / distribution (CT/D). On the other hand, the latter category which discusses supporting components for collaboration can also be divided into several categories based on the types of components used to support the operationalize of collaboration such as: the process of interaction among participants in the network, how to design an integrated systems among participants in the network, and how the decision support system be used in the collaborative environment, etc.

In a complete production process, it is usually initiated from the marketing division where it gets some feedbacks or requirements from end customers of a (new) product. The customer feedback/requirements are then translated into a product design by design and product development division. Then the design information is translated into a product in a manufacturing division and then distributed using transportation to the end customer. The current collaborative manufacturing models are divided into 4 parts which are: $\mathrm{CF}$ model covering collaboration for predicting and determining the exact numbers of demand and supply, CDPD model which covers collaboration in design and product development, CM model which covers collaboration in the production process of a product, and CT/D model which covers collaboration in the product distribution.

Each collaboration model has their advantages as well as disadvantages. The advantages and disadvantages of the models can be viewed from the collaboration models itself or from the holistic process of production. The combination of those current collaboration models into a holistic and comprehensive model will give maximum benefits for the involved companies. The disadvantages of a collaboration model will be covered by discussing the comprehensiveness of the holistic model. However, regardless of the significant benefit of a holistic model of collaboration, we cannot find such a literature which discusses that area.

The discussion in this paper will be arranged as follows: the next section will briefly explore collaborative manufacturing models followed by a review on the four models described above. Then the discussion will continue to explore some gaps identified in the literature analysis and then stress on the next research potential. Finally, conclusions will be drawn.

\section{MODEls OF COLlabORATIVE MANUFACTURING: A BRIEF INTRODUCTION}

Collaborative manufacturing is a relatively new approach which is very powerful in helping manufacturers especially small and medium manufacturers to become more competitive in this current global environment. There are many collaborative models that have been developed by researchers and implemented by many manufacturing companies. However, from the context of a holistic collaborative manufacturing network, many manufacturing companies are still looking for a collaboration network form which is more flexible [28]. Models for collaborative manufacturing must be based on a single process from a manufacturing company which means that each participant (company/part of the company) who get involved in a collaboration network should behave like being a part of a company and must be integrated with each other and working together in order to achieve the sharing company goals which is decided and agreed together [29]. Internal company integration and coordination should be integral in the formation of collaborative manufacturing network which consists of several companies working together.

In a collaborative manufacturing network, each company in the network is not manufacture their own product itself, but instead the production process is distributed among all participant companies through exploitation of each company capabilities and competencies offered by each company in the network [30]. Companies which become members of the network strategically analyse their respective companies which are related to the process or function which have to internalized or externalized for other activities [3]. In a collaboration framework, business process coordination which is interdependent of each other in a network is very important. Coordination is needed as a part of an order fulfilment process. This coordination relationship can support the flow of information, material and process in the network [31].

Management of production facilities among participants is an important aspect in a collaborative manufacturing. A collaboration framework must provide real time production information which can be used by any node in the network including the customer. Sharing business data and information of organizational constraints will help determine network efficiency. The network infrastructure must support connectivity of all participants, between partners and customers and among equipment in every company [15].

Establishing and enhancing commitment and trust in a collaborative manufacturing is a fundamental element for the successful operation of the collaboration [32] and [33]. Establishing trust cannot be achieved instantly; instead it should be developed gradually until is strong enough for smooth collaboration [6]. In this level, each participant will be able to share business information without being fear of being taken over by other participants [13]. Commitment also an important roles in the successful implementation of collaboration by increasing confidence in facilitating collaboration, reducing conflict and generating better outcomes at the collaboration level [34].

Influencing factors for the successful design and implementation of collaborative manufacturing are discussed by some researchers. Reference [13] described that some foundation of formality needs to be established for a collaborative manufacturing to be successful both in the design and implementation, such as alignment, dedication, visibility, accessibility, engagement, security, scalability, culture, and leadership with the most important factor being the human factor. He further describes that the first step needed is to remove obstacles that stand in the way of the collaboration process. 


\section{LITERATURE REVIEW}

The discussion in this section will focus on the four identified collaborative models, the CF model, CDPD model, $\mathrm{CM}$ model, and $\mathrm{CD} / \mathrm{T}$ model.

\section{A. Collaborative Forecasting (CF) Model}

The current collaborative forecasting models mainly cover collaboration for predicting and determining demand and supply both from customers (internal and external) and suppliers. Reference [23] proposes a forecasting collaboration model for networked manufacturing enterprises by establishing mechanisms for transforming customer's independent demand. In their model, both suppliers and customers should be working together by providing information needed by each other.

Other researchers also discuss this CF model but give more stress on the collaborative components for supporting the implementation aspect. Reference [22] discusses seven guidelines for the implementation of inter-firm collaborative forecasting. They stressed on the importance for companies to apply their guidelines in order to succeed in the collaborative process. Reference [35] uses six sigma methodologies to improve the performance of collaborative forecasting in a CPFR. They claimed that the result can improve the accuracy of collaborative forecast. Whereas [36] describe that some influencing factors such as transportation issues during holiday and assembly line maintenance issues must be considered in order to improve forecasting accuracy. Companies who get involved in a collaborative forecasting have reported significant benefits on their supply chain performances.

\section{B. Collaborative Design and Product Development (CDPD) Model}

Models of CDPD are designed to enable participants from geographically different locations in the world to work together simultaneously, facilitates them with basic facilities needed for collaboration, and enables them to access computational resources for collaborative design [19], [37], and [38]. Some of the CDPD current models are used to capture non-functional aspects of the design [20], enabling evaluation of design changes in terms of total manufacturing cost and value of in a collaborative environment [21], and enabling to monitoring and control of complex collaborative new product development projects effectively [17]. Some of the CDPD models have integrated collaborative design and manufacturing activities [39], [40] whereas other models stress on how to handle different discipline, backgrounds and characteristics of participants [41] as well as how to handle potential conflict among participants [42].

The benefits of CDPD models are reported as saving cost and time, shortened product life cycle and improved company productivity [19], and ease in the implementation as new software for new participating companies is not required so reducing financial investment on the system development [37].

\section{Collaborative Manufacturing (CM) Model}

Three models of CM using an intermediary for connecting all information from the network are developed by [2], [8], and [33]. The first model consists of three networks which are the manufacturing network, transportation network, and storage network connected in one company while in the second model consists of several companies in one network. In the third model, the intermediator is in the form of the agency organization service. This agency provides a guideline on collaborative platforms to the participants in a collaborative manufacturing.

Issues in the formation of a manufacturing network get special- attention from some researchers. Reference [25] discussed the reason behind why company would get involved in a collaborative network. Whereas some researchers developed a framework to ease a company into involvement in a dynamic and adaptive collaborative manufacturing network [43], [44].

Other models of CM discuss patterns of manufacturing networks [45], business process coordination in the collaborative manufacturing context [31], [46], and communication protocols for order management in a collaborative manufacturing context [47] which will be of benefit for SMMEs as it does not require an introduction of any new systems.

The interconnection of participants in the collaborative manufacturing network is also getting special attention from some researchers who stress their discussion on data and information sharing [48]-[50], project planning and scheduling [18], [24] and decision support systems [51]-[53].

Most of the researchers identified in this review stress the importance of involving company production activities into the discussion of collaborative manufacturing networks such as the linkage between manufacturing strategies and company production systems and elaborating the relationships in the collaborative production systems [6] and [16].

\section{Collaborative Transportation / Distribution (CT/D) Model}

Most of the researches conducted in a collaborative transportation / distribution are developed from a concept of collaborative transportation management [54], [55]. This is true as the focus discussions in this last model are regarding transportation issues from manufacturer to the customer. Some researches stressed the discussion on the role of information technology [56], on the delivery time and cost reduction [57] and on the coordination aspects in the collaborative transportation [58], [59] while [60], [61] discuss the performance measurements of the network.

The comprehensive model of CT/D is presented in [62]. They connected domestic and international networks to deliver customer orders at a competitive price in a timely manner with guaranteed quality. This can be achieved since they are exploiting the combined network resources and activities as well as sharing market knowledge and local networks to increase capabilities and capacities.

\section{FINDINGS}

Every stage plays a significant role for the successful process of production so that the improvement process of every stage must be done for company competitiveness. In a traditional production process, every stage and its 
improvement efforts are conducted internally by a company using many improvements tools but as the trend for production process in this global environment changes from internal process improvement to the collaborative process improvement, then companies must follow the trend for their competitiveness. Businesses that remain competitive do not only look into its internal operations only but also communicate and work concurrently with all players in the enterprise network [4].

\section{A. Supporting Components of the Current Collaborative Manufacturing Network models}

As discussed, the current fragmented collaborations in the context of production cycle consist of four main collaboration models which are $\mathrm{CF}, \mathrm{CDPD}, \mathrm{CM}$ and CD/T. The role of each collaborative model is important as it enhances the company competitiveness in this current global market. In the CF, participant companies will be enabled to predict and determine demand and supply both from the customer (internal and customer) and supplier collaboratively. In the CDPD, the design and product development of a product can be done concurrently and collaboratively by participants. In the CM, product manufacturing processes are conducted collaboratively by participants companies. Whereas in the CT/D the distribution of a product will be done by some transporters and by working collaboratively with warehousing companies and any other participant in the network.

One important supporting component which is discussed in all collaborative models is the integration and coordination framework in the collaborative network. In the holistic context of collaborative manufacturing network, the discussion on the integration and coordination aspects of collaborative network are very essential as they will determine the successful implementation of collaborative manufacturing network $(\mathrm{CMN})$. In the reviewed papers, coordination and integration are related with the coordinating and integrating of all activities, people, tools, data and information involved in the collaborative network.

In the activities level, it refers to the coordinating design and manufacturing activities [39], [40], linking manufacturing strategies and the production system [1] and [6], and integrating assembly and disassembly activities [63]. In terms of people coordination, it refers to the integrating and cooperating teams from multidisciplinary, background and characteristics [41], [40] from different locations in order to enable modelling of business interactions and dynamic interactions for managing their daily collaborative operations [31], [64]. The linkages for the people coordination are enforced by strong relationship among participants. Tools for coordination and integration involve tools from various autonomous manufacturing work systems to work together in a collaborative environment. All of these coordination and integration aspects should be based on the interdependency and smooth data and information flows among activities, people and tools in the network [16]. This smooth application will facilitate manufacturing network and international operations for participants and is important in the holistic $\mathrm{CMN}$. There should be some guidelines as well for coordinating and integrating those involved in this network
[22]. The guidelines should be described in detail covering the prerequisites, the whole process as well as the rules of the game in the network. Factors which influencing all aspects for the successful operation and its improvements in the collaborative manufacturing network should be considered as well in the network [36].

\section{B. Advantages of the Current Collaborative Manufacturing Network Models}

From the point of view of the collaboration model itself, each model has its own advantages. Many advantages can be achieved if a company is to get involved in a collaboration network. The lists of advantages can be group into three in terms of total cost reduction, shortest delivery time to the customer and highest possible product quality. The total cost reduction reported means the total cost reduction that can be achieved in each collaborative model and not in the context of the whole process in the production cycles. If we assume that each collaboration model gives the same portion of benefit to the total production cycle then the total cost reduction of one collaborative model will only give a quarter of the possible total cost reduction of production cycle. The combination of the total cost reduction achieved in the other three collaborative models will make the complete and maximum total cost reduction for participants in the production cycle. However, there is still little discussion about the whole process model of manufacturing in order to get the combined benefits of these four collaborative models. Maximum benefit of the production cycle is not achieved yet. Reference [13] said that in order to achieve an effective collaborative manufacturing strategies, all aspects involved in the collaborative network must be viewed in a holistic sense.

\section{Potential Research Directions}

Many researchers and industrial practitioners have encourage SMMEs to get involve in a collaborative manufacturing strategy to increase their competitiveness by reducing their production cost, increasing companies capacities and capabilities, fulfilling customer demands, and gaining worldwide market. The involvement of SMMEs in a collaborative manufacturing network will increase SMMEs participation in the global economy which in turn will increase economic contribution to their country. Hence the design of a holistic model which can cover all possible issues and can be used to solve the interaction in the whole process of production is very important. By considering all aspects and issues in the CMN, it is expected that a comprehensive model of CMN can be established and SMMEs can fully benefit from it. The holistic model will assist SMMEs to comprehend the complex interactions among collaborative partners of SMMEs and to facilitate SMMEs to get involved in the network. This is very significant for manufacturing companies since they tend to make and join a collaboration without a clear understanding of the issues and constraints which could lead to business failure. However, despite many advantages, there are still some issues that exist in the SMMEs regarding the model design as well as its implementation which need to be solved. The process for 
collaboration in the collaborative manufacturing network is not simple and easy, instead it is a complex and very dynamic process. Some factors influence the establishment of a successful collaboration such as economic, manufacturing and operational issues. These factors are added with the potential increasing management complexity as manufacturing activities must be shared among participants. These issues as well as new organizational settings of CMN, prevent SMMEs for being part of a successful network.

Combining the advantages of current collaborative models into a comprehensive advantage in a holistic model of collaborative manufacturing network is essential as it will enable SMMEs to be globally competitive and sustainable in this fast changing market. The future of this research area is enormous. However, there are no researches found so far which discuss the comprehensiveness of these potential combined advantages. Even though some participant companies have benefited from a fragmented collaboration, it is expected a great future for a holistic model of CMN and envision future of a holistic collaborative manufacturing network as being:

- Fully integrated with all necessary participants' softwares dispersed in the holistic network which cover all production cycles from customer product feedback for a product design - production - and distribution to the end customer.

- User friendly interface as well as ease for data, information and material exchange.

- Transparent for all conditions within participants in the network.

- Easy in the implementation.

- Secured with sophisticated security and protection system both for individual and network companies.

In order to achieve this vision, a number of challenging issues have been identified for future researches. Among others, the following areas are believed to be the future research opportunities:

- Mapping the participants and its relationship. Participants and their relationship are not defined yet. The definition is important for designing interaction among participants in the CMN.

- Information requirements. Information needed for interactions among them are based on the required information for each activity. It should be defined and be put in a holistic collaborative information structure.

- Communication protocols. In the holistic CMN, communication among participants is very important. Protocol for helping participants communicate effectively and efficiently in the network is essential.

- Models for holistic collaborative manufacturing network. It is a research challenge for formulating a business collaboration model in the context of a comprehensive model of collaborative manufacturing network (CMN).

- Integration and coordination. Integration should enable efficient operation management and control among heterogeneous business entities. The discussion on holistic integration and coordination should include activities, people, tools, data and information.

- Interoperability. The system should be adaptive and dynamic and enable participants to do an efficient work and control and to handle any kinds of interaction in the network.

- Planning and scheduling. In the context of holistic CMN, the design of project planning begins from very early in the production cycle until products are delivered to the end customer.

- Decision support system (DSS). Many of the information and decision processes such as production, managerial and economics are still controlled separately by various members participating in a collaborative model. DSS should enable participants to decide whether to join, leave or decide any issues related to their involvement in this collaborative network.

- Transportation and distribution management. The transportation issues should be discussed and cover a comprehensive aspect of logistic network.

- Performance measurement. The performance measurements should be conducted both in internally within a company and intra-company in terms of cost, time and quality.

- Security and privacy. Issues of security and privacy in the holistic CMN are very important to be addressed where practical techniques and application should be developed to ensure the protection of participants and the network system.

The successful delivery of this holistic CMN will be beneficial to worldwide SMMEs as it will increase significantly their competitiveness in a global environment. Furthermore, it will ease and enable SMMEs to justify their involvement and collaboration in a CMN based on the performance evaluation.

\section{CONCLUSION}

Each model in the four models of collaborative manufacturing discussed above represent part of the production cycle. The potential benefits of model combination between models or among models in a holistic collaborative manufacturing model are not fully explored yet especially for the advantages of SMMEs. Hence, this paper reviewed those potential model combination benefits, identified a number of challenging issues and proposed some suggestions for future researches. The areas in the future research opportunities are enormous and the discussion of those areas will enable SMMEs to take maximum benefit of the holistic models and be able to be globally competitive and sustainable in this fast changing market. The discussion of the holistic model which covers all possible issues will assist SMMEs to comprehend the complex interaction among collaborative participants and to facilitate SMMEs to get involved in the network. This is very important since they tend to involved in a collaboration without a clear understanding of the issues and constraints which could lead to business failure.

\section{ACKNOWLEDGMENT}

The first author would like to acknowledge the University of Hasanuddin Makassar and Directorateof Higher Education Indonesia (DIKTI) which granted the scholarship to carry out this research. 


\section{REFERENCES}

[1] M. Winroth and M. Danilovic, "Linking manufacturing strategies to design of production systems in collaborative manufacturing networks," in Proc. the 14th Annual Conference of the Production and Operations Management Society, Savanna, Georgia, USA, 2003.

[2] L. Chunquan and Z. Dejian, "Study on small and medium enterprises collaborative manufacturing system based on agency organization services," in Proc. International Technology and Innovation Conference, pp. 1014-1019, 2006.

[3] S. D. Amours, B. Montreuil, P. Lefrancois, and F. Soumis, "Networked manufacturing: The impact of information sharing," International Journal of Production Economics, vol. 58, pp. 63-79, 1999.

[4] K. L. Choy, W. B. Lee, and V. Lo, "An enterprise collaborative management system - a case study of supplier relationship management," The Journal of Enterprise Information Management, vol. 17, no. 3, pp. 191-207, 2004.

[5] S. A. Rosenfeld, "Does cooperation enhance competitiveness? Assessing the impacts of inter-firm collaboration," Research Policy, vol. 25, pp. 247-263, 1996.

[6] M. Danilovic and M. Winroth, "A tentative framework for analysing integration in collaborative manufacturing network settings: A case study," Journal of Engineering and Technology Management, vol. 22 , pp. 141-158, 2005

[7] S. A. Sherer, "Critical success factors for manufacturing networks as perceived by network coordinators," Journal of Small Business Management, vol. 41, no. 4, pp. 325-345, 2003.

[8] H. Noori and W. B. Lee, "Dispersed network manufacturing: Adapting SMEs to compete on the global scale," Journal of Manufacturing Technology Management, vol. 17, no. 8, pp. 1022-1041.

[9] L. T. Ho and G. C. I. Lin, "Critical success factor framework for the implementation of integrated-enterprise systems in the manufacturing environment," International Journal of Production Research, vol. 42 no. 17, pp. 3731-3742, 2004.

[10] E. Mazzola, M. Bruccoleri, and G. Perrone, "A strategic framework for firm networks in manufacturing industry: An empirical survey," $C I R P$ Annals - Manufacturing Technology, vol. 58, pp. 387-390, 2009.

[11] Mesa International. (2004). Collaborative manufacturing explained. [Online]. Available: http://www.mesa.org.

[12] L. Wang, "Wise-Shop floor: A portal toward collaborative manufacturing," Springer, 2007.

[13] M. McClellan, "Collaborative manufacturing: A strategy built on trust and cooperation," Control Solution International, vol. 12, pp. 27-31, 2003.

[14] N. Bilbao, D. D. Pozo, D. J. M. Lopez, and I. Etxaniz, "The collaborative manufacturing approach," IEEE International Conference on Industrial Informatics, 2004.

[15] ARC Advisory Group, Collaborative Manufacturing Management Strategies, Thought Leaders for Manufacturing and Supply Chain, 2002.

[16] K. Johansen, M. Comstock, and M. Winroth, "Coordination in collaborative manufacturing mega-networks: A case study," Journal of Engineering and Technology Management, vol. 22, pp. 226-244, 2005.

[17] C. H. Chen, S. F. Ling, and W. Chen, "Project scheduling for collaborative product development using DSM," International Journal of Project Management, vol. 21, pp. 291-299, 2003.

[18] L. Wang, Y. Song, and W. Shen, "FBD: A function block designer for distributed and collaborative process planning," CSCWD 2005, LNCS 3865, pp. 434-444, 2006.

[19] H. F. Zhan, W. B. Lee, C. F. Cheung, S. K. Kwok, and X. J. Gu, “A web based collaborative product design platform for dispersed network manufacturing," Journal of Material Processing Technology, vol. 138, pp. 600-604, 2003.

[20] D. Alisantoso, L. P. Khoo, I. B. H. Lee, and W. F. Lu, "A design representation scheme for collaborative product development," International Journal of Advanced Manufacturing Technology, no. 30, pp. 30-39, 2006.

[21] Y. J. Tseng, Y. W. Kao, and F. Y. Huang, "A model for evaluating a design change and the distributed manufacturing operations in a collaborative manufacturing environment," Computers in Industry, vol. 59, pp. 798-807, 2008.

[22] T. M. McCarthy, and S. L. Golicic, "Implementing collaborative forecasting to improve supply chain performance," International Journal of Physical Distribution \& Logistics Management, vol. 32, no. 6, pp. 431-454, 2002

[23] R. Poler, J. E. Hernandez, J. Mula, and F. C Lario, "Collaborative forecasting in networked manufacturing enterprises," Journal of
Manufacturing Technology Management, vol. 19, no. 4, pp. 514-528, 2008.

[24] W. L. Chen, C. Y. Huang, and Y. C Lai, "Multi-tier and multi-site collaborative production: Illustrative by a case example of TFT-LCD manufacturing," Computers and Industrial Engineering, 2008.

[25] C. R. Monroy and J. R. V. Arto, "Analysis of global manufacturing virtual networks in the aeronautical industry," International Journal of Production Economics, vol. 126, pp. 314-323, 2010.

[26] P. Danese, "The extended VMI for coordinating the whole supply network," Journal of Manufacturing Technology Management, vol. 17, no. 7, pp. 888-907, 2006

[27] J. Jiao, X. You, and A. Kumar, "An agent-based framework for collaborative negotiation in the global manufacturing supply chain network," Robotics and Computer-Integrated Manufacturing, vol. 22 pp. 239-255, 2006.

[28] W. Colombo, R. Schoop, P. Leitao, and F. Restivo, "A collaborative automation approach to distributed production systems," IEEE, 2004.

[29] J. Cai, S. C. Y. Lu, F. Grobler, M. Case, and N. Jing, "Modeling and managing collaborative processes over the internet," Business Process Management Journal, vol. 11, no. 3, pp. 255-274, 2005

[30] F. T. S. Chan and S. H. Chung, "Multicriterion genetic optimization for due date assigned distribution network problems," Decision Support Systems, vol. 39, pp. 661-675, 2005.

[31] L. Cloutier, J. M. Frayret, S. D. Amours, B. Espinasse, and B Montreuil, "A commitment-oriented framework for networked manufacturing co-ordination," International Journal of Computer Integrated Manufacturing, vol. 14, no. 6, pp. 522-534, 2001.

[32] S. L. Jack, "Approaches to studying networks: Implications and outcomes," Journal of Business Venturing, 2008

[33] S. Nagalingam and O. M. Fretes, "Integration of small and medium manufacturing enterprises through collaborative partnership," in Proc. the 7th ANZAM Operations, Supply Chain and Services Management Symposium, pp. 312-325, 2009

[34] N. Clarke, "The relationships between network commitment, its antecedents and network performance," Management Decision, vol. 44, no. 9, pp. 1183-1205, 2006

[35] K. K. Chang and F. K. Wang, "Applying six sigma methodology to collaborative forecasting," International Journal of Advanced Manufacturing Technology, vol. 39, pp. 1033-1044, 2008.

[36] T. Shu, S. Chen, S. Wang, and K. K. Lai, "Supply chain collaborative forecasting methods on the basis of factors," in Proc. the 2008 IEEE ICMIT, 2008.

[37] X. Mi, W. Shen, and W. Zhao, "Research on internet-based system architecture for collaborative product development," CSCWD 2005, LNCS 3865, pp. 439-403, 2005.

[38] L. Q. Fan, A. S. Kumar, B. N. Jagdish, and S. H. Bok, "Development of a distributed collaborative design framework within peer-to-peer environment," Computer-Aided Design, vol. 40, pp. 891-904, 2008.

[39] A. Sluga, P. Butala, and J. Peklenik, "A conceptual framework for collaborative design and operations of manufacturing work systems," CIRP Annals - Manufacturing Technology, vol. 54, issue 1, pp. $437-$ 440, 2005.

[40] C. Vila, A. Estruch, H. R. Siller, J. V. Abellán, and F. Romero, "Workflow methodology for collaborative design and manufacturing," LNCS 4674, pp. 42-49, 2007.

[41] D. Shi, J. Yin, W. Zhang, J. Dong, and D. Xiong, "A distributed collaborative design framework for multidisciplinary design optimization," CSCWD, LNCS 3865, pp. 294-303, 2006.

[42] L. G. Yesilbas and M. Lombard, "Towards a knowledge repository for collaborative design process: Focus on conflict management," Computers in Industry, vol. 55, pp. 335-350, 2004.

[43] B. Montreuil, J. M. Frayret, and S. D’Amours, "A strategic framework for networked manufacturing," Computers in Industry, vol. 42, pp 299-317, 2000.

[44] V. Zaletelj, A. Sluga, and P. Butala, "A conceptual framework for the collaborative modeling of networked manufacturing systems," Concurrent Engineering, vol. 16, pp. 103-114, 2008.

[45] Y. Shi and M. Gregory, "International manufacturing networks-to develop global competitive capabilities," Journal of Operations Management, vol. 16, pp. 195-214, 1998

[46] J. M. Frayret, S. D'Amours, B. Montreuil, and L. Cloutier, "A network approach to operate agile manufacturing systems," International Journal of Production Economics, vol. 74, pp. 239-259, 2001.

[47] C. Y. Huang, T. S. Huang, and W. L. Chen, "Communication protocols for order management in collaborative manufacturing," International Journal of Production Economics, vol. 122, pp. 257-268, 2009. 
[48] M. Danilovic, "Bring your suppliers into your projects-Managing the design of work packages in product development," Journal of Purchasing and Supply Management, vol. 12, pp. 246-257, 2006.

[49] G. Jain, "Data transport and sharing for collaborative manufacturing industry," Asia Pacific Science and Technology Centre, 50 Nanyang Avenue, 2006.

[50] M. Pouly, S. Naciri, and S. Berthold, "Collaborative manufacturing management in networked supply chains," IFIP International Federation for Information Processing, AICT 307, pp. 136-145, 2009.

[51] H. W. Lin, S. V. Nagalingam, and M. Chiu, "Development of a collaborative decision making model for a network of manufacturing SMEs," in Proc. the $18^{\text {th }}$ International Conference on Production Research, University of Salermo, Italy, 2005.

[52] H. W. Lin, S. V. Nagalingam, and G. C. L. Lin, "An interactive meta-goal programming based decision analysis methodology to support collaborative manufacturing," Robotics and Computer-Integrated Manufacturing, vol. 10, no. 005, pp. 1-20, 2007.

[53] H. W. Lin, S. V. Nagalingam, and G. C. I. Lin, "Towards collaborative manufacturing in small and medium manufacturing enterprises," in Proc. the 35th International MATADOR Conference, National Taiwan University, Taipei, Taiwan, Springer-Verlag London, 2007b.

[54] C. M. Feng and C. Y. Yuan, "Application of collaborative transportation management to global logistics: An interview case study," International Journal of Management, vol. 24, no. 4, pp. 623-636, 2007.

[55] F. T. S. Chan and M. T. Zhang, "The impact of collaborative transportation management on supply chain performance: A simulation approach," Expert Systems with Applications, vol. 38, pp. 2319-2329, 2011.

[56] T. L. Esper and L. R. Williams, "The value of collaborative transportation management (CTM): Its relationship to CPFR and information technology," Transportation journal, vol. 42, issue 4, pp. $55-65,2003$.

[57] J. C. Tyan, F. K. Wang, and T. Du, "Applying collaborative transportation management in global third party logistics," International Journal of Computer Integrated Manufacturing, vol. 16, no. 4-5, pp. 283-291, 2003.

[58] X. F. Yin and L. P. Khoo, "A hierarchical model for e-supply chain coordination and optimization," Journal of Manufacturing Technology Management, vol. 18, no. 1, pp. 7-24, 2007.

[59] Z. M. Udin, M. K. Khan, and M. Zairi, "A collaborative supply chain management framework Part 1 - planning stage," Business Process Management Journal, vol. 12, no. 3, pp. 361-376, 2006.

[60] T. M. Simatupang and R. Sridharan, "A benchmarking scheme for supply chain collaboration," Benchmarking: An International Journal, vol. 11 no. 1, pp. 9-30, 2004.

[61] P. J. Singh, "Improving lead times through collaboration with supply chain partners: Evidence from Australian manufacturing firms,' Department of Management and Marketing, University of Melbourne-Parkville, Australia, 2007.
[62] S. M. H. Bernal, C. Burr, and R. E. Johnsen, "Competitor network: International competitiveness through collaboration, the case of small freight forwarders in the high-tech forwarder network," International Journal of Enterpreneurial Behaviour and Research, vol. 8, no. 5, pp. 239-253, 2002.

[63] G. Ostojic, V. Jovanovic, B. Stevanov, S. Stankovski, and I. Cosic, "Collaborative design in the assembly systems," Digital Enterprise Technology-Perspectives and Future Challenges, eds PF Cunha and PG Maropoulos, Springer Science and Business Media, LLC, 233 Spring Street, New York, NY 10013, USA, 2007.

[64] M. Rudberg and B. M. West, "Global operations strategyCoordinating manufacturing networks," The International Journal of Management Sciences, vol. 36, pp. 91 - 106, 2008.

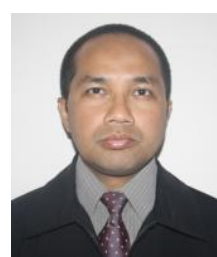

Mohammad Rizal Firmansyah is currently doing his Ph.D. research degree at the University of South Australia under Indonesian Government Scholarship. He has worked in a Shipyard Industry for 1 year before being a Lecturer in Engineering Faculty Hasanuddin University, Indonesia. Since 2012, he became an International Member of the Society of Naval Architects and Marine Engineers (SNAME). He obtained his BA in Naval Architecture in 1997 from Hasanuddin University, Indonesia, MEng in Marine Material and Production Engineering in 2002 from 10 Nopember Institute of Technology, Indonesia and MEng in Manufacturing Management from University of South Australia in 2009. He has involved in a number of collaborative researches with Shipyard Industries in Indonesia as well as with Indonesian Classification Bureau.

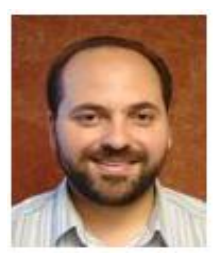

Yousef Amer obtained his Ph.D. in 2007 from the University of South Australia and developed a nove quantitative model to optimise supply chain processes using design for Six Sigma and fuzzy logic. He has worked in manufacturing and logistics for over 18 years. Dr Yousef Amer is a Lecturer and Program Director at the School of Advanced Manufacturing and Mechanical Engineering in University of South Australia. He has published many international peer reviewed research papers in the research fields of supply chain management, sustainability in manufacturing, integration and performance measurement, and business process re-engineering, three book chapters and two books. He is a member of the Barbara Hardy Institute, the Council of Supply Chain Professionals (CSCMP), Logistics Association of Australia (LAA), Chartered Institute of Purchasing and Supply (CIPS) and the Performance Measurement Association (PMA) 